

\section{En el planeta Ingmar Bergman}

\section{Artículo de reflexión}

Recibido: 12 de agosto 2018

Aprobado: 20 de septiembre de 2018

\author{
Sandro Romero Rey \\ Universidad Distrital Francisco José de Caldas, \\ Colombia \\ sandroromero@yahoo.com
}

Cómo citar este artículo: Romero Rey, Sandro (2019). En el planeta Ingmar Bergman. Estudios Artísticos: revista de investigación creadora, 5(6) pp. 30-43. DOI: https://doi. org/10.14483/25009311.14098

\section{(c) (i)}

https://creativecommons.org/licenses/by/4.0/deed.es

$<$

Playa de Fårö donde fue filmada PERSONA (1966).

Fotografía: León García Jordán (2018).

\section{Resumen}

Fårö es una isla situada en el mar Báltico, al norte de la isla de Gotland. Allí, el director de cine sueco Ingmar Bergman estableció su residencia, donde rodaría algunas de las películas más importantes de su filmografía. El presente texto, es el resultado de un viaje al epicentro creativo de uno de los realizadores más importantes de la historia. La obra de Bergman, tanto para el teatro, como para la radio, el cine y la televisión, representa uno de los mejores ejemplos de lo que dio a llamarse "la creación de autor". Poseedor de un estilo único y desgarrador, Bergman se aferró a los oficios de la representación con toda la vehemencia de un explorador radical de los asuntos de la vida y de la muerte. "El séptimo sello", “Persona”, “Vergüenza”, “La hora del lobo", "Escenas de un matrimonio", "Fanny y Alexander", entre muchas otras, forman parte del patrimonio artístico de la humanidad y recorrer los pasos de su gestor se convierte en una obra de arte en sí misma: trayecto de iniciación hacia los misterios de una industria que, gracias a los artificios de personalidades insustituibles como la de Ingmar Bergman, representa hoy por hoy, el triunfo de un estilo y de una tradición sin concesiones.

\section{Palabras claves}

Cine de autor; Ingmar Bergman; crítica de cine; creación de autor

\section{On planet Ingmar Bergman}

\section{Abstract}

Fårö is an island in the Baltic Sea, north of the island of Gotland. Swedish film director Ingmar Bergman established his residence there, and he would shoot on the island some of the most important films of his filmography. What follows is the result of a trip to 
the creative epicenter of one of the most important filmmakers in history. Bergman's work for theater, radio, film and television represents one of the best examples of what he called "the creation of an author". Possessing a unique and heart-wrenching style, Bergman clung to the power of representation with all the vehemence of a radical explorer of the affairs of life and death. "The Seventh Seal", "Persona", "Shame", "Hour of the Wolf", "Scenes from a Marriage", "Fanny and Alexander", among many others, are part of the artistic heritage of humanity and walking in the steps of their creator becomes a work of art in itself: a journey of initiation into the mysteries of an industry that, thanks to the craftmanship of irreplaceable personalities like Ingmar Bergman, conveys today the triumph of a style and an unrelenting tradition.

\section{Keywords}

Author cinema; Ingmar Bergman; film criticism; author creation

\section{Sur la planète Ingmar Bergman}

\section{Résumé}

Fårö est une île située dans la mer Baltique, au nord de l'île de Gotland. Là-bas, le réalisateur suédois Ingmar Bergman a établi sa résidence, où il tournerait certains des films les plus importants de sa filmographie. Ce texte est le résultat d'un voyage à l'épicentre créatif de l'un des plus importants cinéastes de l'histoire. Le travail de Bergman, à la fois pour le théâtre, la radio, le cinéma et la télévision, représente l'un des meilleurs exemples de ce qu'il appelle «la création d'un auteur». Possédant un style unique et déchirant, Bergman s'accrochât aux pouvoirs de la représentation avec toute la véhémence d'un explorateur radical des affaires de la vie et de la mort. Le Septième sceau, Persona, La Honte, L'Heure du loup, Scènes de la vie conjugale, Fanny et Alexandre, entre autres, font partie du patrimoine artistique de l'humanité et marcher dans les pas de leur créateur devient une œuvre d'art en soi : parcours d'initiation dans les mystères d'une industrie qui, grâce aux artifices de personnalités irremplaçables telles que Ingmar Bergman, représente aujourd'hui le triomphe d'un style et une tradition sans concessions.

\section{Mots clés}

Cinéma d'auteur ; Ingmar Bergman ; critique de film ; création d'auteur

\section{No planeta Ingmar Bergman}

\section{Resumo}

Fårö é uma ilha localizada no Mar Báltico, ao norte da ilha de Gotland. Lá, o diretor de cinema sueco Ingmar Bergman estabeleceu sua residência, onde ele iria filmar alguns dos filmes mais importantes de sua filmografia. Este texto é o resultado de uma viagem ao epicentro criativo de um dos cineastas mais importantes da história. O trabalho de Bergman para teatro, rádio, cinema e televisão representa um dos melhores exemplos do que ele chamou "a criação de um autor". Possuindo um estilo único e comovente, Bergman se agarrava aos poderes da representação com toda a veemência de um explorador radical dos assuntos da vida e da morte. "O Sétimo Selo", “Persona”, “Vergonha", “A Hora do Lobo", "Cenas de um Casamento", "Fanny e Alexander", entre muitos outros, fazem parte do património artístico da humanidade e refazer os passos de seu criador torna-se uma obra de arte em si: caminho de iniciação nos mistérios de uma indústria que, graças aos artifícios de personalidades insubstituíveis como Ingmar Bergman, hoje representa o triunfo de estilo e uma tradição sem concessões.

\section{Palavras-chaves}

Cinema de autor; Ingmar Bergman; crítica de cinema; criação de autor

\section{Kai mundupi kasa suti kagta Ingmar Bernan}

\section{Maillallachiska}

Sug uchuia alapa tiaska kai sug iakupi suti karkasi kasa atun iaku Baltuku, sug iluarrmasi sutikarka sug uchuia alpapi Gothand, chipi sug runa imasami kawachidurkaski iapa suma kawarigta suti kagta filmografía kai kilkaikunapi kami, kaskami imasami ririrka sug chaima kai kaskakuna iapa suma rurarkakuna.

Kai ruraikuna kai suti runa kagta Bergman, chasa imasami kawachingapa kagta, imasami, kawangapa kagta atunpi, sacha tukurka iapa allila kawachirii "imasami kairuna rurarka", imasami kai trabajo 
ruraikuna Tukui imasa kai kuna, Bergman, kai imasami wañui kari kai kanchis kagta " runa" "iakirii tiaska”, kai luva, kawachiriska kasaraipi, " Fanny i Alexander" i sug kunapipas tiaska, kai chasa tiaska kai kilkaikunapi kai runakuna imasam kaugsai tiarka kai sug luarkunapi, imasami kaiarirkakuna sug tsabajukunapi kachaiatuta tiarka sug luarpi mana tiarkachu mana pudirkuna tupakungapa sug runakunawa imasami kai runa karka Bergman chasami kawachi imasami ruraka iapa i antiwamandaiatata imasami rurarkakuna.

\section{Rimangapa Ministidukuna}

Kawachingapa atunpi kai. Ingmar Bergman; iapa rimai tiaskamanda kai kawachiskamanda; imasami kai trabajakuna ruraka kai runa rurag

El 14 de julio de 1918, nació uno de los directores de cine más importantes del mundo: el creador de Un verano con Mónica y El séptimo sello, de El manantial de la doncella y Fresas salvajes, de Los comulgantes y El rito, de Gritos y susurros y Fanny y Alexander. Cien años después, Suecia ha comenzado las celebraciones del acontecimiento, no solo consolidando la imagen del maestro en el billete de 200 coronas, sino concentrando las principales actividades en el microcosmos del genio: Fårö (la isla de los corderos). Fue allí, comenzando la década del 60, donde Ingmar Bergman descubrió su paraíso. Buscando locaciones para su película Como en un espejo, se encontró, en la mitad del mar Báltico, un territorio que se convertiría en su morada hasta el fin de sus días y en el territorio de cinco películas, dos documentales y una serie de televisión que paralizó su país y luego se introdujo en el mundo por las vías de las salas de cine: Escenas de la vida conyugal. La saga creativa en Fårö es, quizás, una mínima parte en la producción de un maestro absoluto que realizó cerca de 60 largometrajes, 125 obras de teatro mal contadas, programas de radio, versiones para televisión y una buena cantidad de libros que consolidaron su viejo anhelo de convertirse en escritor. La obra de Bergman es descomunal tanto en calidad como en cantidad y su nombre es un referente inmediato para todos los amantes del llamado "cine de autor". Pero lo que sucedió en Fårö no tiene comparación. Sin saberlo, los largometrajes realizados en su isla sagrada (la citada Como en un espejo, Persona, Vergüenza, La hora del lobo, La pasión de Ana) se convertirían en la consolidación de un estilo y en

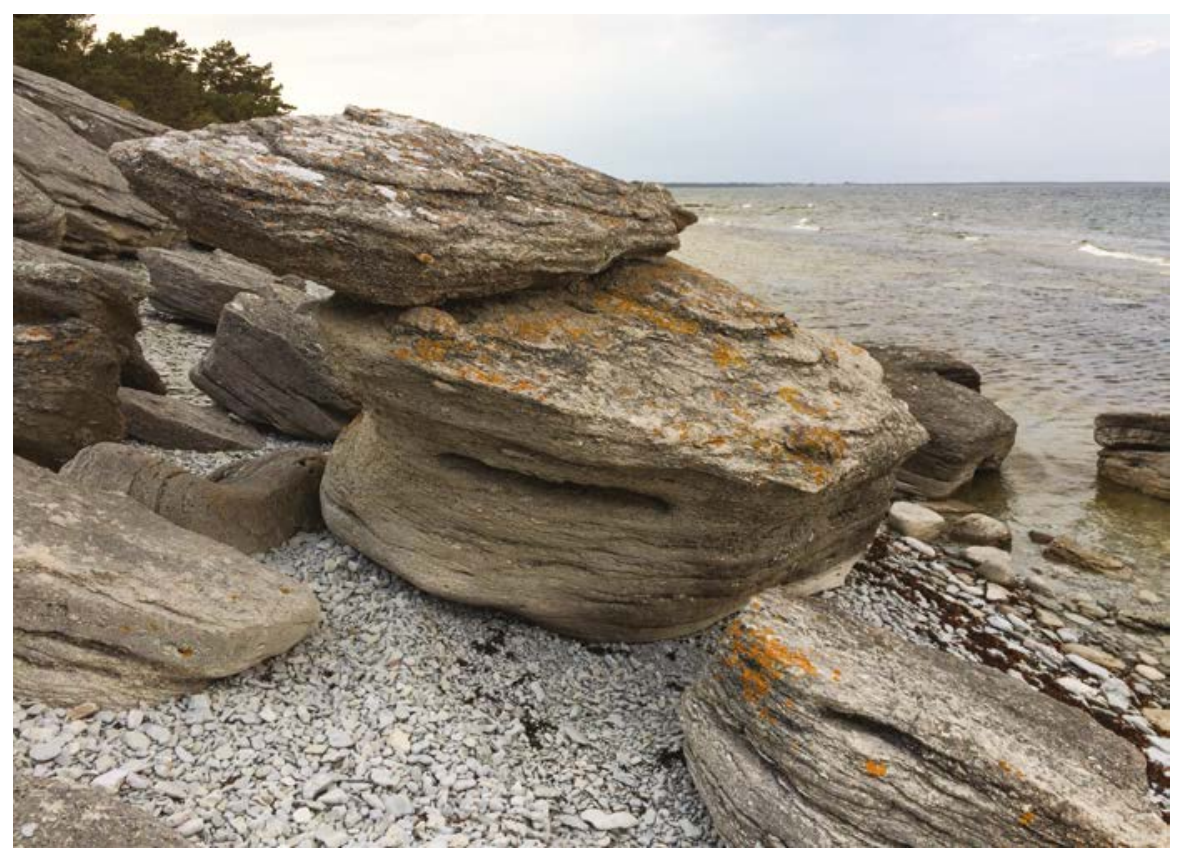

Imagen 1. Playa de Fårö donde fue filmada COMO EN UN ESPEJO (1960). Fotografía: León García Jordán (2018). 
el encuentro de sus desaforadas búsquedas en las cavernas de los seres humanos. Ir a buscar dicho territorio es una aventura en la que la ficción aspira a convertirse en realidad.

Si el viajero curioso no vive en Suecia, para llegar a Fårö debe atravesar el mundo. En primer lugar, hay que arreglárselas para llegar a Estocolmo, la ciudad donde Bergman realizaría buena parte de su creación artística. De allí, hay que desplazarse en tren durante una hora hasta el puerto de Nynäshamn, al este del país. Al llegar al mar, hay que instalarse en un ferry durante 4 horas, para hacer una segunda escala, ahora en la isla de Gotland, en la mitad del Báltico. En el elegante puerto de Visby, donde los suecos viven el verano como el mejor regalo de los dioses nórdicos, se toma un coche hacia el norte de la isla. Luego, se debe instalar en un viejo ferry amarillo (que el bergmaniano aguzado podrá reconocerlo en dos de sus películas) y, en media hora, se encontrará en Fårö. Allí, todas las percepciones cambian. No. No se trata, en sentido estricto, de "la isla de Bergman", como la han llamado en algunas producciones audiovisuales. El territorio del maestro es una parte del oriente de la isla, donde se encuentran las playas prehistóricas que conformaron el paisaje de sus films. Allí construyó Bergman su casa que, hoy por hoy, es un templo de la cinefilia (el director Alejandro González Iñárritu lo dice sin tapujos en el documental Trespassing Bergman (Jane Magnusson, Hynek Pallas, 2013): "si el cine fuese una religión, este lugar sería La Meca"). Cerca de su morada, hay otras casas que fue construyendo, a lo largo de los años, para invitar a los miembros de su inmensa familia ( 9 hijos, 6 esposas, nietos, colegas...). A pocos minutos, en Dämba, hay un antiguo establo, convertido en sala de proyección privada para 15 espectadores, a pocos minutos de su residencia. $Y$, desde hace ya largos 10 años, Fårö cuenta con el Bergman Center, donde se concentra la información sobre la obra del genio, que el viejo Ingmar alcanzó a visitar antes de su muerte, la cual ocurrió el 30 de julio de 2007, el mismo día en que se fuese para siempre el director italiano, Michelangelo Antonioni.

Entre el 25 de junio y el 1 de julio de 2018, se desarrolló una nueva edición de la Bergmanveckan (la Semana Bergman) en Fårö, donde se combinaron los homenajes y las reflexiones alrededor de la obra del director de El rostro, con la presencia de sus viejos cómplices, junto a las presentaciones de nuevos artistas estimulados por el espectro del artista. Aquellos que tienen el privilegio de ser aceptados en las residencias para creadores de Fårö, cuentan con la posibilidad de visitar la casa donde Bergman trabajó, vivió y murió. Es un lugar extraordinario e íntimo, un extenso rectángulo dividido en varias habitaciones, donde se destaca la gran chimenea y el salón principal, uno de los lugares en los que la documentalista, Marie Nyreröd, escogiese para conversar con Bergman en su trilogía "Bergman och filmen", "Bergman och teatern", "Bergman och Fårö", realizada en 2004 para la televisión sueca. Los espacios, construidos con pinzas por su habitante principal, se extienden a lo largo: un cuarto para la meditación, otro con las paredes tomadas por casetes de VHS y un televisor para las noches de insomnio, el lecho nupcial donde moriría su última esposa, Ingrid y después, el mismo Bergman, tras varios años de reclusión final en la helada isla de sus profundos encantos. A un extremo, la biblioteca, cerrada al público por culpa de los ladrones de ocasión, donde hay de todo, de Strindberg a García Márquez, de traducciones de sus propios libros a copias autografiadas de sus amigos (Ingrid Bergman, Woody Allen, Liv Ullmann...).

En la sala privada de Dämba hay proyecciones para 15 privilegiados espectadores. Según cuentan sus allegados, el viejo director veía dos películas (a las tres y a las siete de la tarde) luego de sus caminatas y sus religiosas jornadas de escritura. En la Semana Bergman, los proyectores de 35 $\mathrm{mm}$. se encendieron para presentar las películas filmadas en Fårö y una función especial de El circo de Chaplin, que el director proyectaba todos los años para sus familiares en el día de su cumpleaños. A 15 minutos de Dämba, se concentran las principales actividades en el Bergman Center (aunque hay otros espacios en la isla para conferencias y proyecciones). Si se revisa el programa se destaca la presencia de Ingmar Bergman Jr., antiguo piloto, ahora interesado en la producción de audiovisuales (Through The Coreographer's Eye) o la de la citada Marie Nyreröd con su nueva investigación (The Undefeated Woman), sobre Gun Bergman, una de "las mujeres" del realizador. Especial atención representó el testimonio de la legendaria Katinka Faragó, asistente y script del maestro (de Tarkovski y de Bo Widerberg...), o la inesperada visita sorpresa de la directora alemana, 


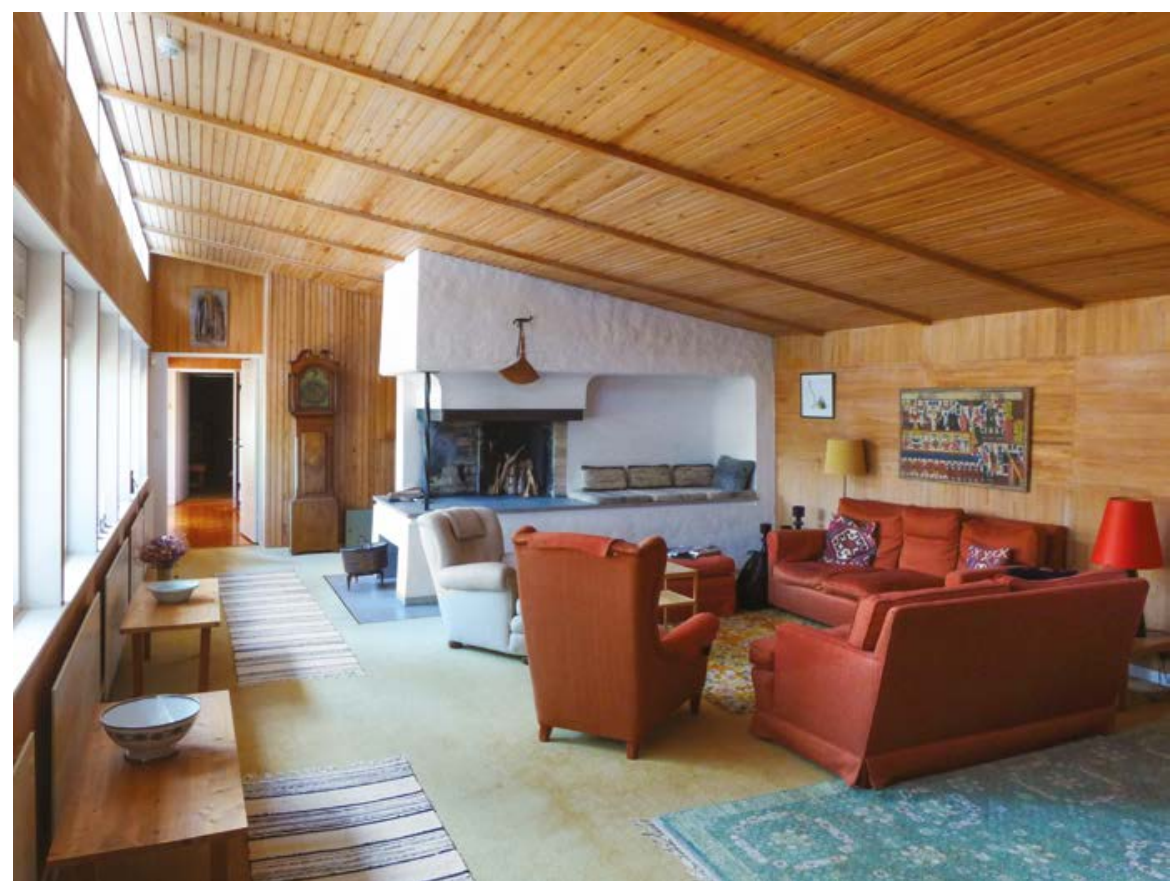

Imagen 2. Salón de Ingmar Bergman con su célebre chimenea de inspiración rusa.

Fotografía: León García Jordán (2018).

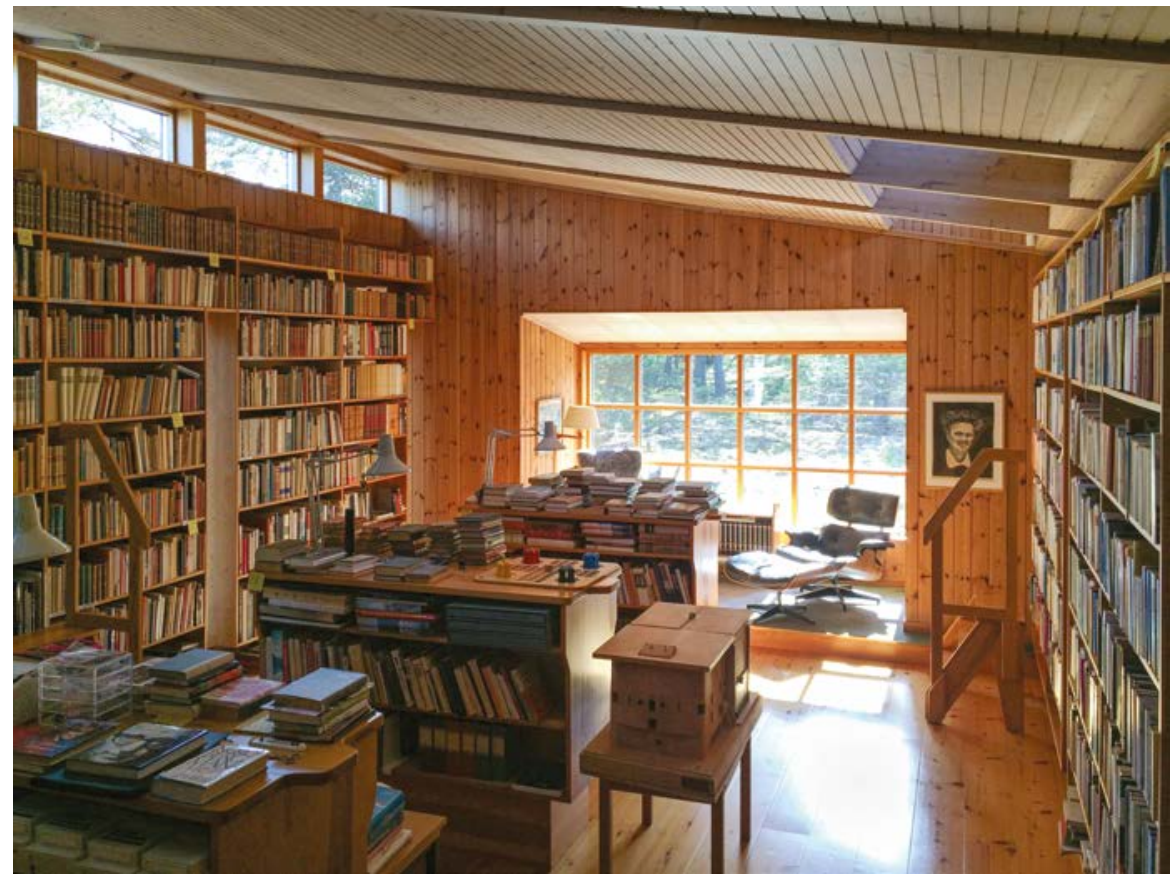

Imagen 3. Biblioteca de Ingmar Bergman en Fårö. Fotografía: León García Jordán (2018). 


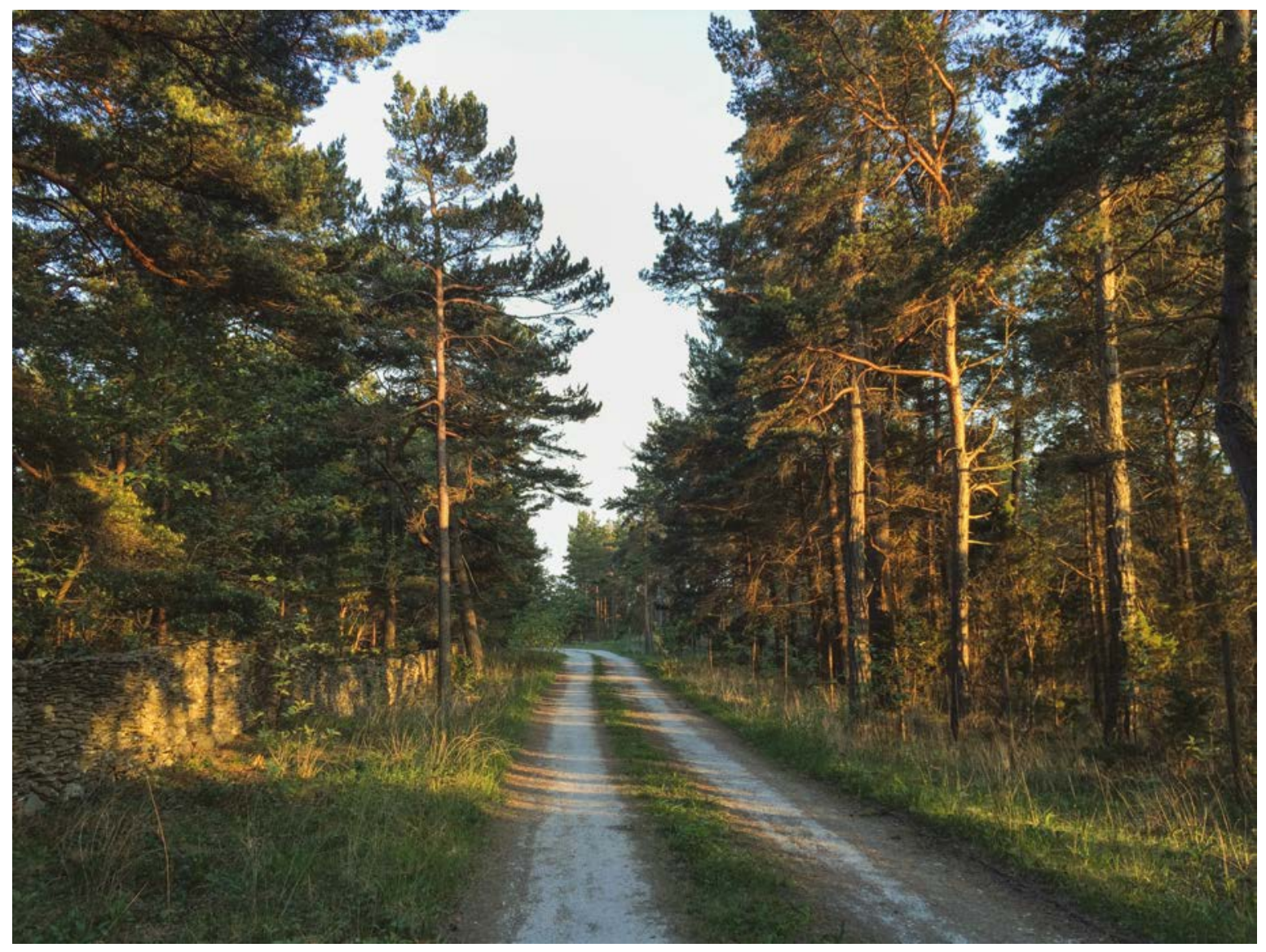

imagen 4. Carretera oculta que conduce a la casa de Ingmar Bergman en Hammars, Fårö. Fotografía: León García Jordán (2018).

Margarethe von Trotta, quien estrenó, en la edición de mayo del Festival de Cannes, su documental In Search of Ingmar Bergman, continuando la saga de apasionantes investigaciones audiovisuales sobre los laberintos creativos del monstruo (entre los que se destaca el apasionado Liv \& Ingmar de Dheeraj Akolkar, sobre l'histoire d'amour entre el director y la actriz noruega Liv Ullmann, protagonista de buena parte de sus films esenciales). El documental de von Trotta se presentó en sesión exclusiva en Fårö. Hay charlas sobre vestuario y dirección de arte, sobre la herencia y la subasta del legado material del maestro (tema que apasiona a tirios y troyanos y que daría para cientos de páginas legales sobre el asunto) o esperadas presencias como la del joven director de culto, griego, Yorgos Lanthimos. Para completar las curiosidades, hay una tarde "bohemia" en el único bar de rock de la isla, donde los fanáticos se preparan para el complicadísimo Bergmanquiz, con preguntas para cinéfilos de gruesa fibra: ¿cuál era el apodo de la actriz Harriet Anderson? ¿A qué actriz llamaba "su Stradivarius"? Si logra responder las 18 preguntas, el desquiciado ganador se lleva la caja con 50 películas de la filmografía del homenajeado. En la tienda del Bergman Center se consigue a 400 dólares.

Pero el verdadero tesoro de la Bergmanveckan es la locación que la acoge. Es Fårö. Los responsables del evento organizan un "Bergmansafari", para pasear por la isla y ubicar los lugares esenciales de sus películas. Pero no es necesario inscribirse en el recorrido. En la isla todo respira a Ingmar Bergman y a Sven Nykvist (su prodigioso director de fotografía), a la actriz Bibi Anderson, al actor Max von Sydow. El cielo de Fårö en el verano se pinta de todos los colores entre las tres de la mañana y la medianoche, donde se le rinde tácito homenaje al libro de memorias de Nykvist, cuyo título es El culto a la luz. Las playas son de piedra y monolitos interplanetarios, nos 


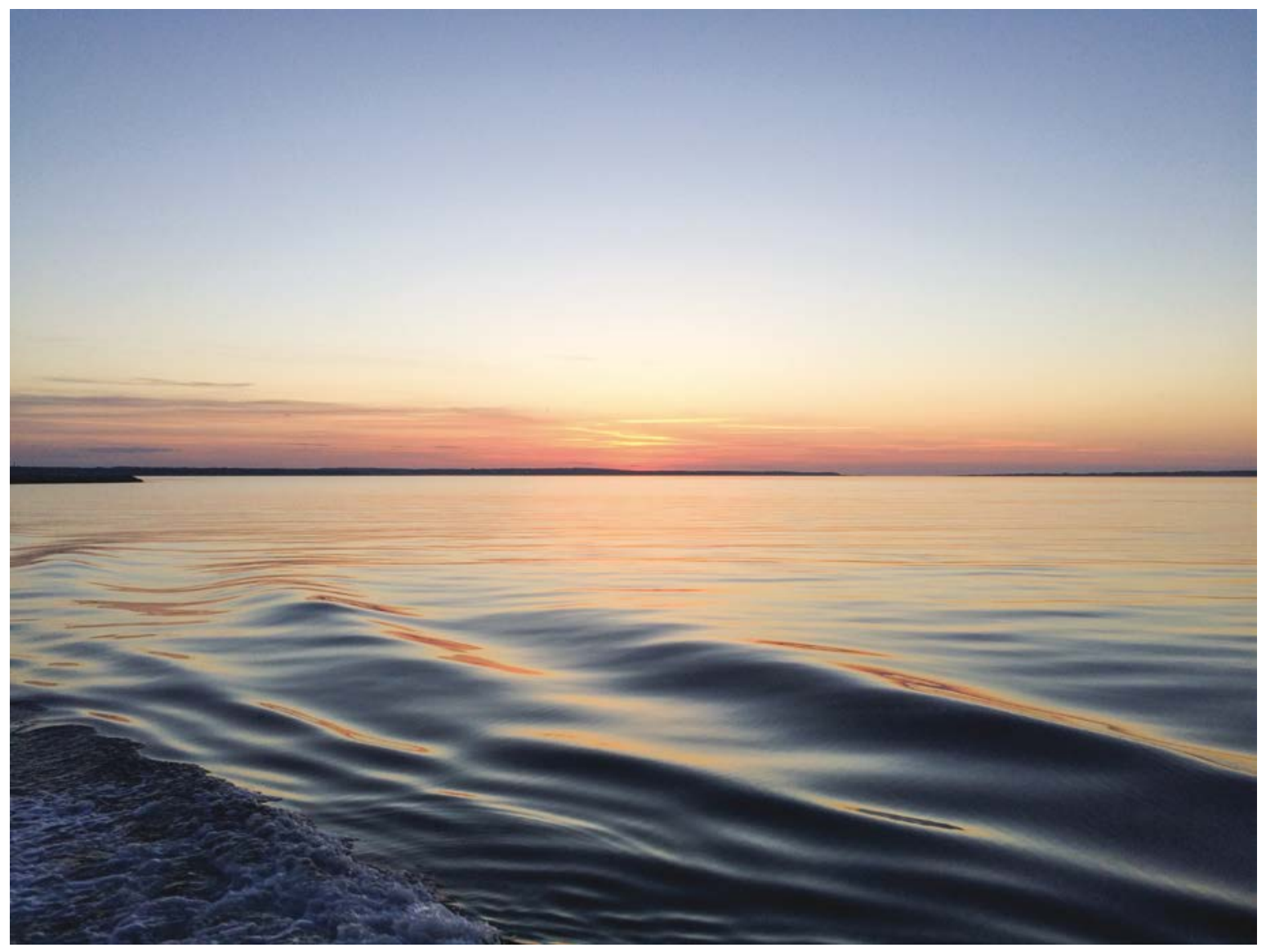

Imagen 5. Vista desde el Ferry que conduce de Fårösund a la isla de Fårö. Fotografía: León García Jordán (2018).

dejan la sospecha de que no se está solo en este mundo sin Bergman. No hay hoteles a la vista. Así que el visitante debe asegurarse de conseguir una vivienda alquilada entre los lugareños y saber convivir con la solitaria simpatía de todos aquellos que se encargan de mantener a flote la barca del cine. Al contrario de lo que sucede en La pasión de Ana, no parece haber desquiciados en la isla. Por lo menos no se vislumbran en el helado verano sueco de sus playas. Sin embargo, para todo aquel que proviene de otros climas, no deja de ruborizar la idea de tener que vivir allí los inviernos de noches eternas y temperaturas que compiten con las de los extremos más bajos de la Tierra. La locura se instala en todo aquel que se imagina las frías y solitarias noches de Bergman a sus 89 años en Fårö.

En el Planeta Bergman hay dos clases de habitantes: los lugareños y los obsesivos estudiantes del entorno. A Fårö llegan de todas partes: noruegos (el mundo de Bergman está rodeado de noruegos) que estudian a Kant y cuentan los días para emborracharse sin clemencia el día del solsticio de verano; visitantes de los países del este europeo, tan próximos a los dolores del alma. En el 2018, se destacaba el investigador colombiano León García, quien ha viajado en varias ocasiones a la isla y conoce de los secretos de Bergman tanto o más que sus 5 esposas. Todos a una se prestan, sin mayores esfuerzos, a la ceremonia inaugural de la Semana, en la kyrka (iglesia) de Fårö, donde un concierto de antiguos "residentes" da la largada al evento, seguido por las emotivas palabras de la reverenda Agneta Söderdahl, quien fuese la encargada de la ceremonia fúnebre de Ingmar Bergman y que ahora subraya los nexos espirituales del artista con la isla. Al salir del templo, si el visitante se adentra por el cementerio aledaño, se encontrará con una piedra tallada en la que se lee: Ingrid Bergman 1930- 1995 / Ingmar Bergman 1918-2007. 


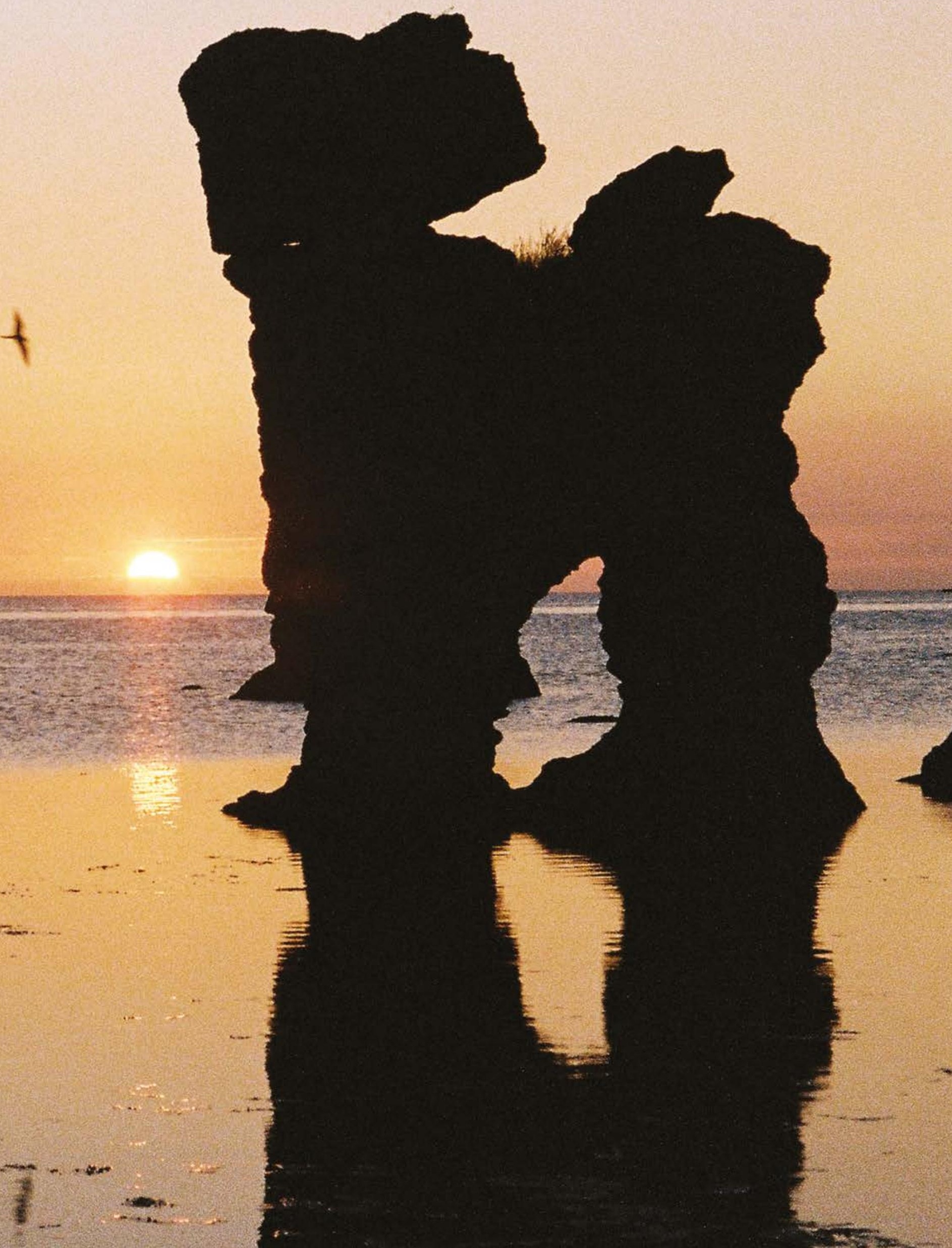




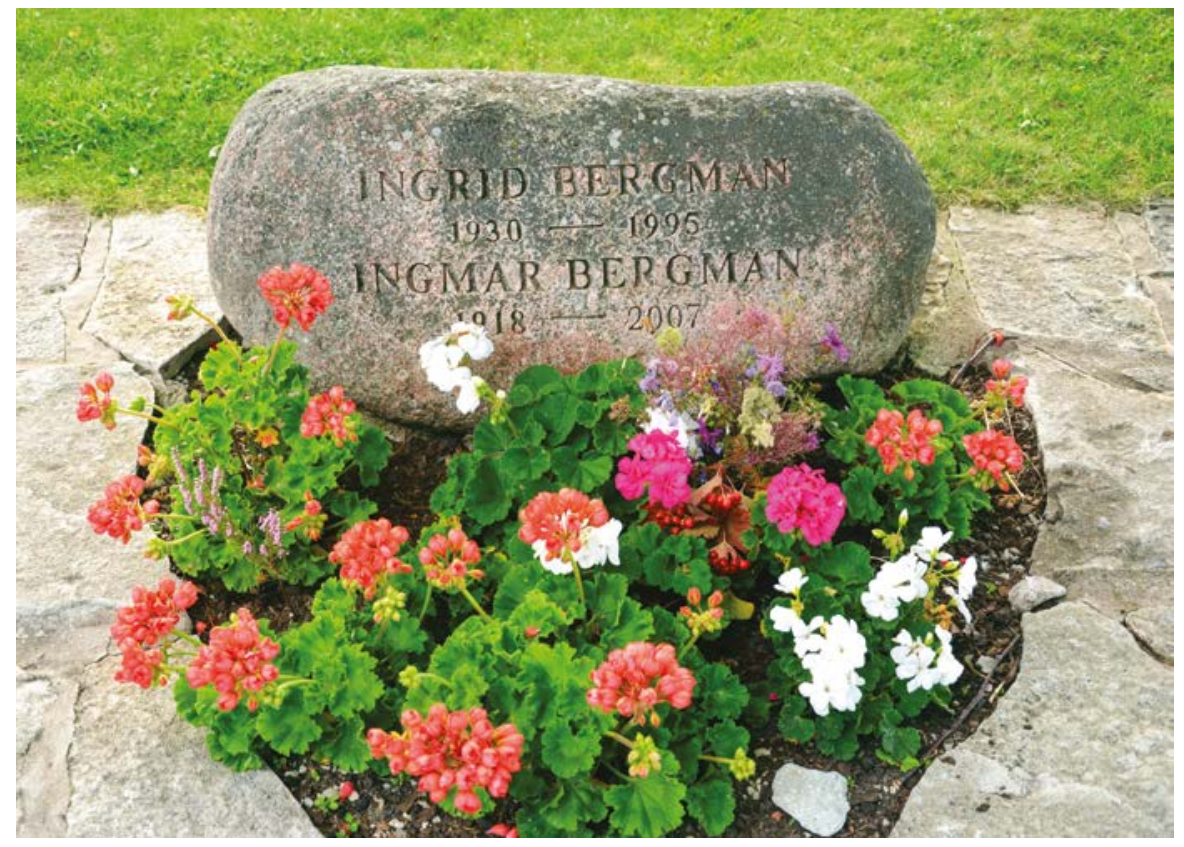

Imagen 7. Tumba de Ingmar Bergman y de su mujer Ingrid von Rosen, en el cementerio de Fårö. Fotografía: León García Jordán (2018).

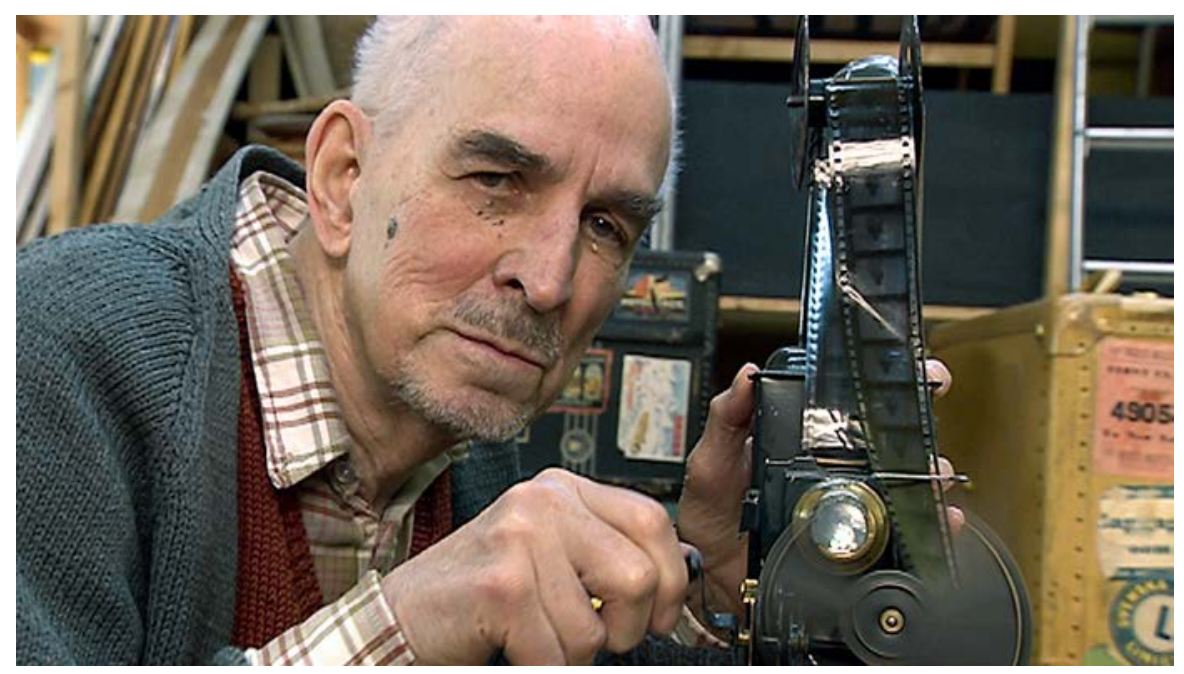

Imagen 8. Ingmar Bergman en Bergman Island (2004), de Marie Nyreröd. Imagen cortesía del Swedish Institute para publicaciones sobre Bergman,2018. 


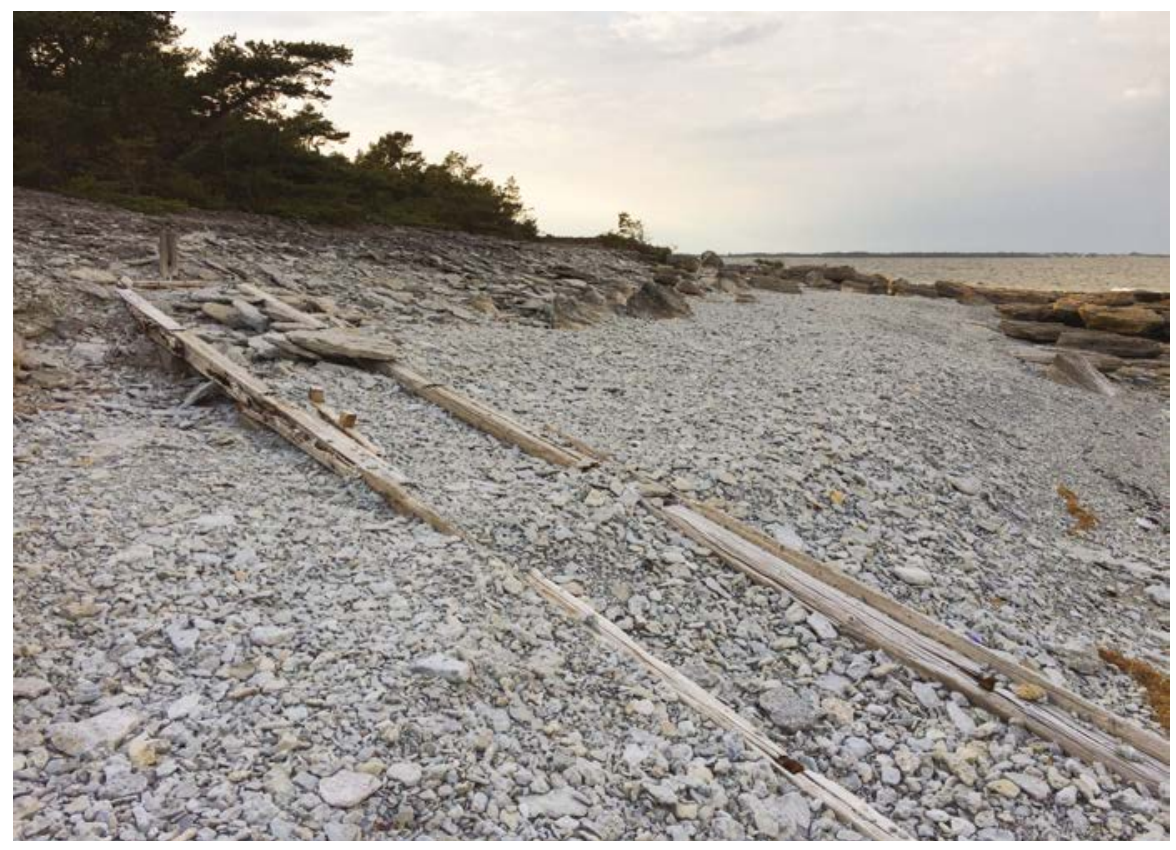

Imagen 9. Vestigios de travelling del rodaje de PERSONA (1966).

Fotografía: León García Jordán (2018).

El suelo que acoge los restos de la última esposa del maestro y los huesos invencibles del creador de En presencia de un payaso, se presentan como una sorpresa discreta, íntima, adicional, para todos aquellos que van a Fårö, como aquel que sigue el camino de Santiago.

Pero si se quiere tener un panorama completo de la geografía de Ingmar Bergman, hay que regresar a Estocolmo, donde se realizó otra parte de su inmensa filmografía y, sobre todo, hay que detenerse en el Dramaten, el Teatro Real de Estocolmo, que fuese el segundo hogar del director, donde puso en escena buena parte de su producción teatral. "El teatro fue mi esposa y el cine mi amante", decía el promiscuo Ingmar Bergman y así lo confirmaron los privilegiados suecos que siguieron, una tras otra, sus emblemáticas puestas en escena, desde sus reconstrucciones de Strindberg, Mishima, Gombrowicz o Molière, hasta sus aventuras con la ópera (The Rake's Progress de Stravinski, Las bacantes de Bergman/Daniel Börtz, La flauta mágica de Mozart...). Hoy por hoy, se está reivindicando al Ingmar Bergman escritor. Así que no es extraño encontrar, en las carteleras teatrales de Londres, Berlín o Estocolmo, obras de teatro a partir de sus films. Ya son clásicas las películas con guiones de Bergman (Las mejores intenciones de Bill August, los títulos de Liv Ullmann, Los Niños del domingo de su hijo Daniel Bergman...). Un paisaje creativo para consolidar la imponencia de un clásico de nuestro tiempo, de un autor que acogió la regla de su padre, el implacable pastor Erik Bergman: "pase lo que pase nunca dejes de celebrar la misa". La misa de Ingmar Bergman no ha terminado. Su obra se multiplica en el cine, en el teatro, en la literatura. Hoy por hoy, se sigue estrellando contra el mundo y sigue cuestionando y poniendo en tela de juicio las correcciones morales y políticas. No. No es tan fácil "matar" a Ingmar Bergman. Al contrario, en Fårö o en Estocolmo y, sobre todo, en los cines, se mantiene victorioso. 100 años después de su nacimiento, una ínsula noble del arte se mantiene intacta, gracias al espectro de Fårö. Aquel intenso creador a quien aún la muerte se le ha quedado pequeña. 


\section{Referencias}

Björkman, S., Manns, T., y Sima, J. (1975). Conversaciones con Ingmar Bergman. Barcelona, España: Editorial Anagrama.

Bergman, I. (1996). Conversaciones íntimas. Barcelona, España: Tusquets Editores.

(2018). (1955-1974), Cuadernos de trabajo. Madrid,

España: Nórdica Libros.

. (1992). Imágenes, Barcelona. España. Tusquets Editores.

(1992). Las mejores intenciones. Barcelona, España:

Tusquets Editores.

(1987). Linterna mágica. Barcelona, España: Tusquets

Editores.

(1997). Niños del domingo. Barcelona, España: Tusquets

Editores.
Fårö and Ingmar Bergman. (2015). A Mutual Bond. Fårö, Suecia: Fårö Local Heritage Association Publishers.

Fundación Bergman. (2008). The Ingmar Bergman Archives. Erland Josephson, Paul Duncan y Bengt Wanselius (Eds.) Colonia, Alemania: Taschen.

Romero, R. S. (2017). El objetivo y la máscara: la tragedia griega en el cine. Estudios Artísticos, 3(3), pp. 98-117. doi: https://doi. org/10.14483/25009311.12531

Siögren, H. (2002). Lek och Raseri. Ingmar Berman Teater 19382002. Stockholm: Carlssons.

Steene, B. (2006). Ingmar Bergman: A Reference Guide. Ámsterdam, Holanda: Ámsterdam University Press.

Ullmann, L. (1979). Senderos. España: Círculo de lectores.

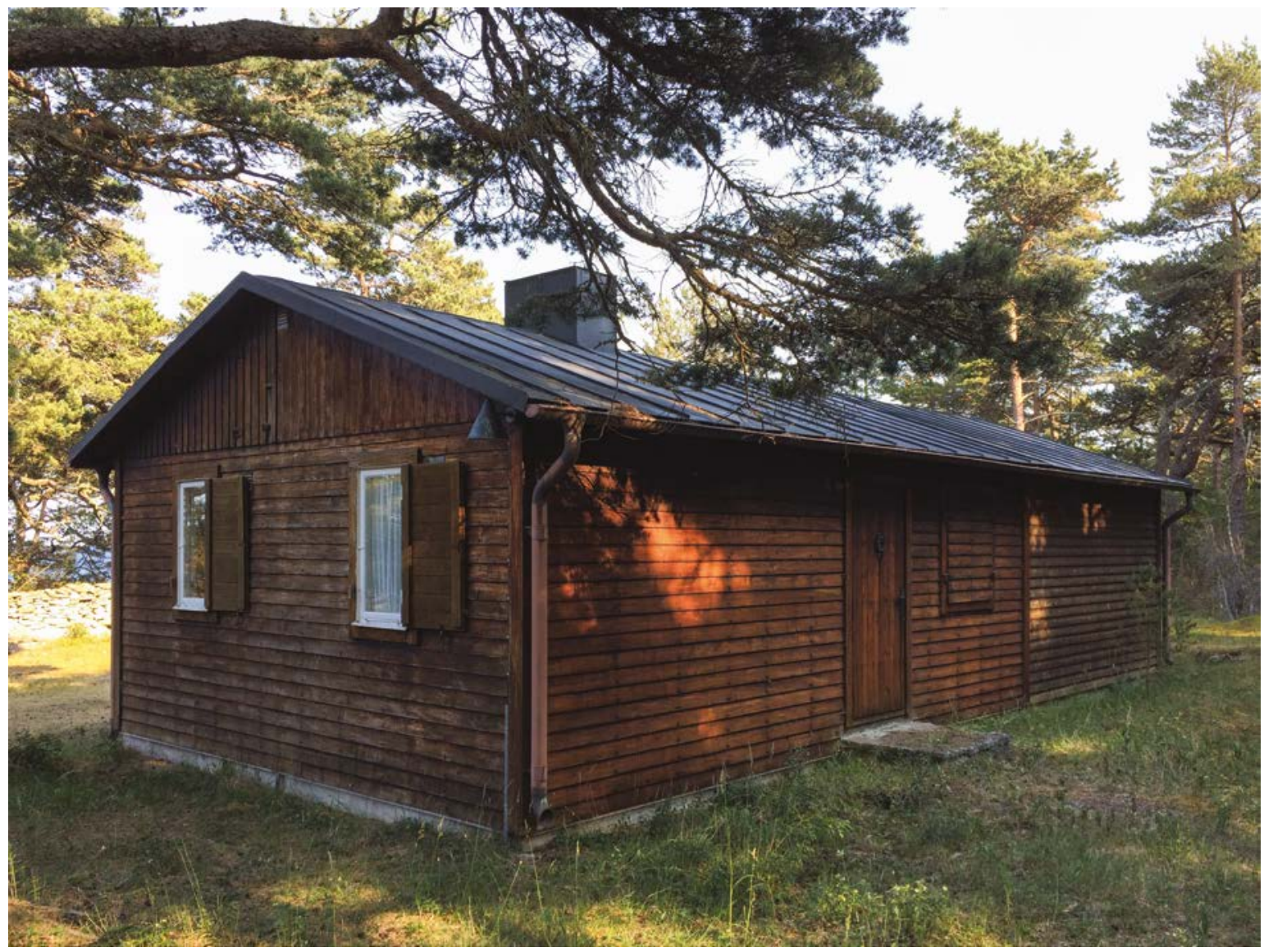

Imagen 10. Skrivstugan, "la cabaña del escritor", a unos metros de la casa de Bergman en Fårö y donde fue filmada ESCENAS DE LA VIDA CONYUGAL (1974). Fotografía: León García Jordán (2018). 


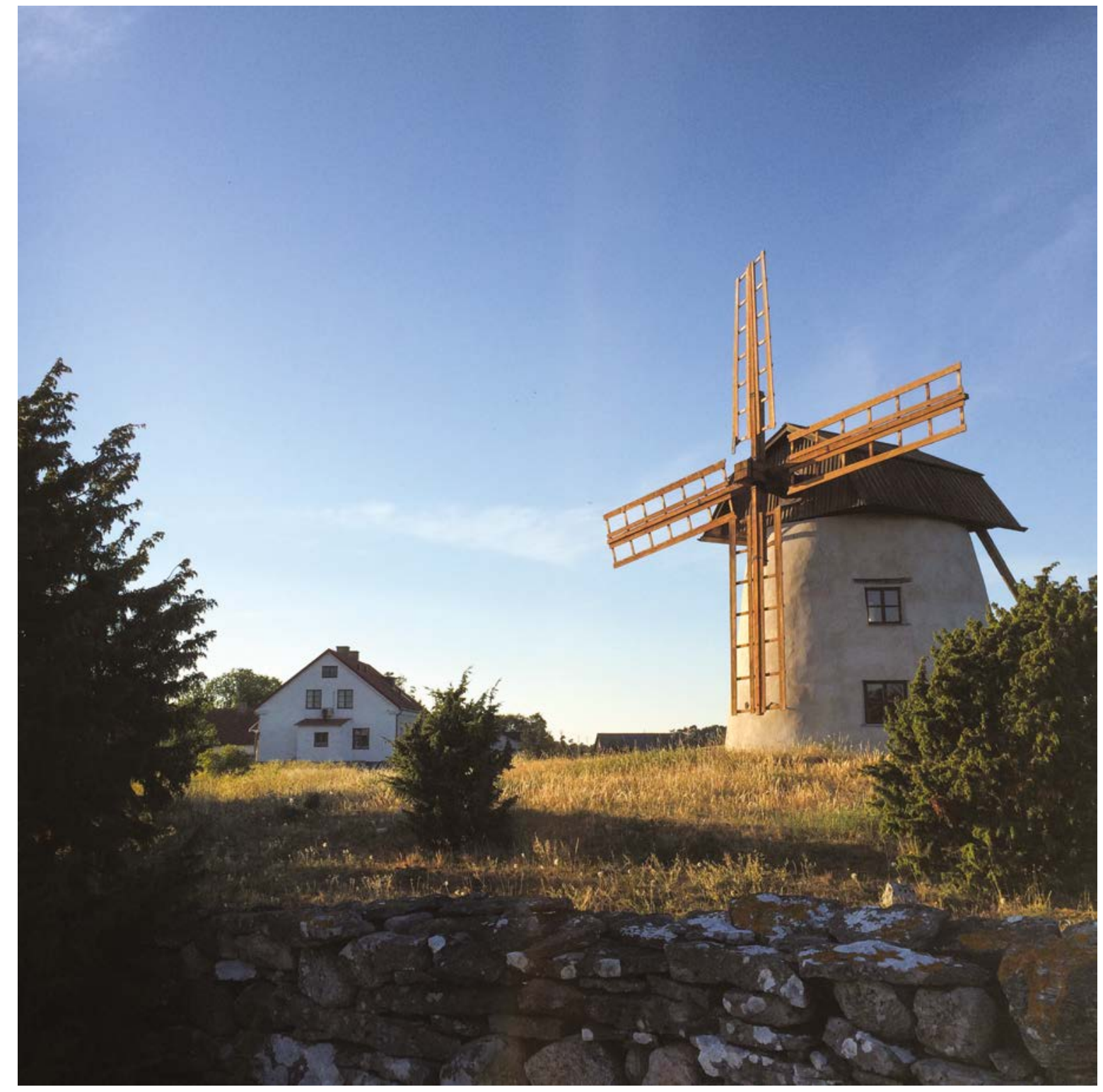

Imagen 11. Casas y molino de Ingmar Bergman en Dämba, Fårö. Fotografía: León García Jordán (2018). 